\title{
Gross Total Resection of Large Cervical Intramedullary Ependymoma: Demonstration of Microsurgical Techniques
}

\section{Büyük Servikal Omurilik Ependimomunun Mikrocerrahi Teknik ile Gross Total Çıarnlmasi: Mikrocerrahi Teknik Demonstrasyonu}

\author{
Ulas CIKLA, Chiristopher BAGGOTT, Mustafa K. BASKAYA \\ University of Wisconsin, Neurological Surgery, Madison, Wisconsin, USA
}

Corresponding Author: Mustafa K. BASKAYA / E-mail: m.baskaya@neurosurgery.wisc.edu

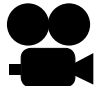

To watch the surgical videoclip, please visit http://turkishneurosurgery.org.tr/images/12847_video.mp4

\begin{abstract}
In adolescents and young adults, ependymomas are the most common intramedullary tumors in the spinal cord.These tumors arise from ependymal cell lining the ventricles and spinal canal. The clinical presentation of intramedullary ependymomas are variable and nonspecific. They usually present with diffuse back or neck pain as a chief complaint. Upper and lower motor neuron deficits, numbness which typically progresses from distal to proximal, are other common symptoms. Gross total resection of ependymomas can achieve long-term tumor control with preservation of function. Here we present a 29-year old man who presented with progressive weakness of the left leg, bowel and bladder incontinence. During surgery, somatosensory evoked potentials (SSEPs) and motor evoked potentials (MEPs) were used and we achieved gross total resection while preserving the spinal cord. The patient made excellent recovery and all of his preoperative deficitis improved completely. He returned to work on postoperative 2-month.
\end{abstract}

KEYWORDS: Ependymoma, Microsurgery, Intramedullary tumor

öz

Adölesanlarda ve genç yetişkinlerde ependimomlar omuriliğin en sık görülen intramedüller tümörleridir. Bu tümörler ventriküller ve spinal kanalı döşeyen ependimal hücre tabakasından köken alır. İntramedüller ependimomların klinik sunumu değişkendir ve spesifik değildir. Genellikle temel şikayet olarak yaygın bel veya boyun ağrısıyla ortaya çıkarlar. Üst ve alt motor nöron defisitleri ve tipik olarak distalden proksimale ilerleyen parestezik yakınmalar diğer sık görülen belirtilerdir. Ependimomların gross total rezeksiyonu işlev korunmasıyla birlikte uzun dönemli tümör kontrolü sağlayabilir. Burada, sol bacakta ilerleyici zayıflı ile birlikte bağırsak ve mesane inkontinansı ile gelen ve cerrahi tedavi uygulanan 29 yaşında bir erkek olguyu sunuyoruz. Cerrahi sırasında somatosensörial uyarılmış potansiyel (SSEP)'ler ve motor uyarılmış potansiyel (MEP'ler takip edildi ve omurilik korunarak gross total rezeksiyon elde edildi. Hasta mükemmel bir iyileşme gösterdi ve tüm preoperatif defisitler tamamen düzeldi. Ameliyat sonrası 2. ayda hasta işine geri döndü.

ANAHTAR SÖZCÜKLER: Ependimom, Mikrocerrahi, Omurilik tümörü 


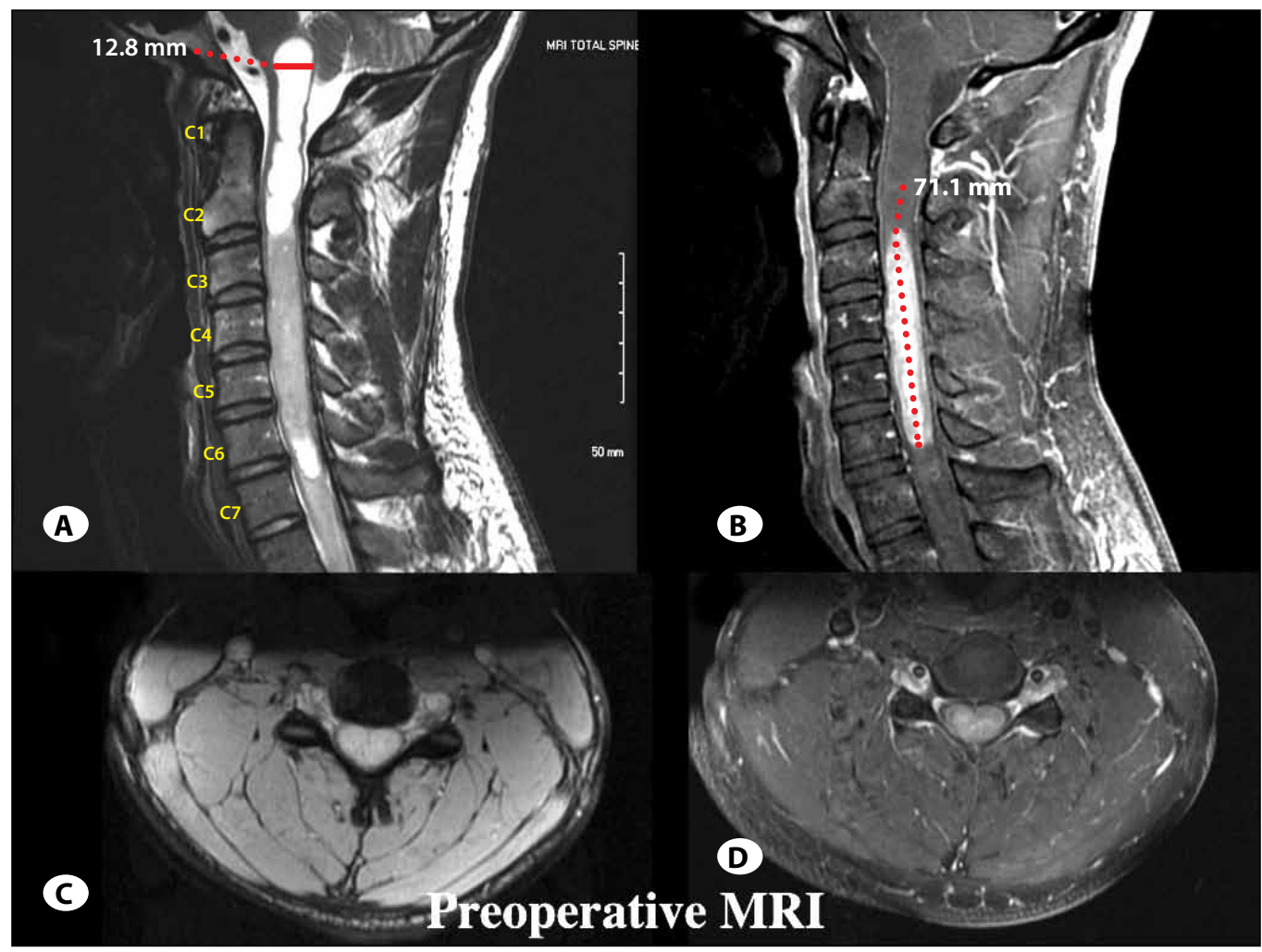

Figure 1: Preoperative images; A) sagittal T2 weighted MRI reveals an intramedullary mass with a large rostral syrinx and a small caudal syrinx, B) postcontrast sagittal T1 weighted MRI reveals a homogenously enhancing intramedullary mass measuring $71.1 \mathrm{~mm}$ rostrocaudally. C) Precontrast axial T2 weighted axial MRI D) postcontrast T1 weighted axial MRI.

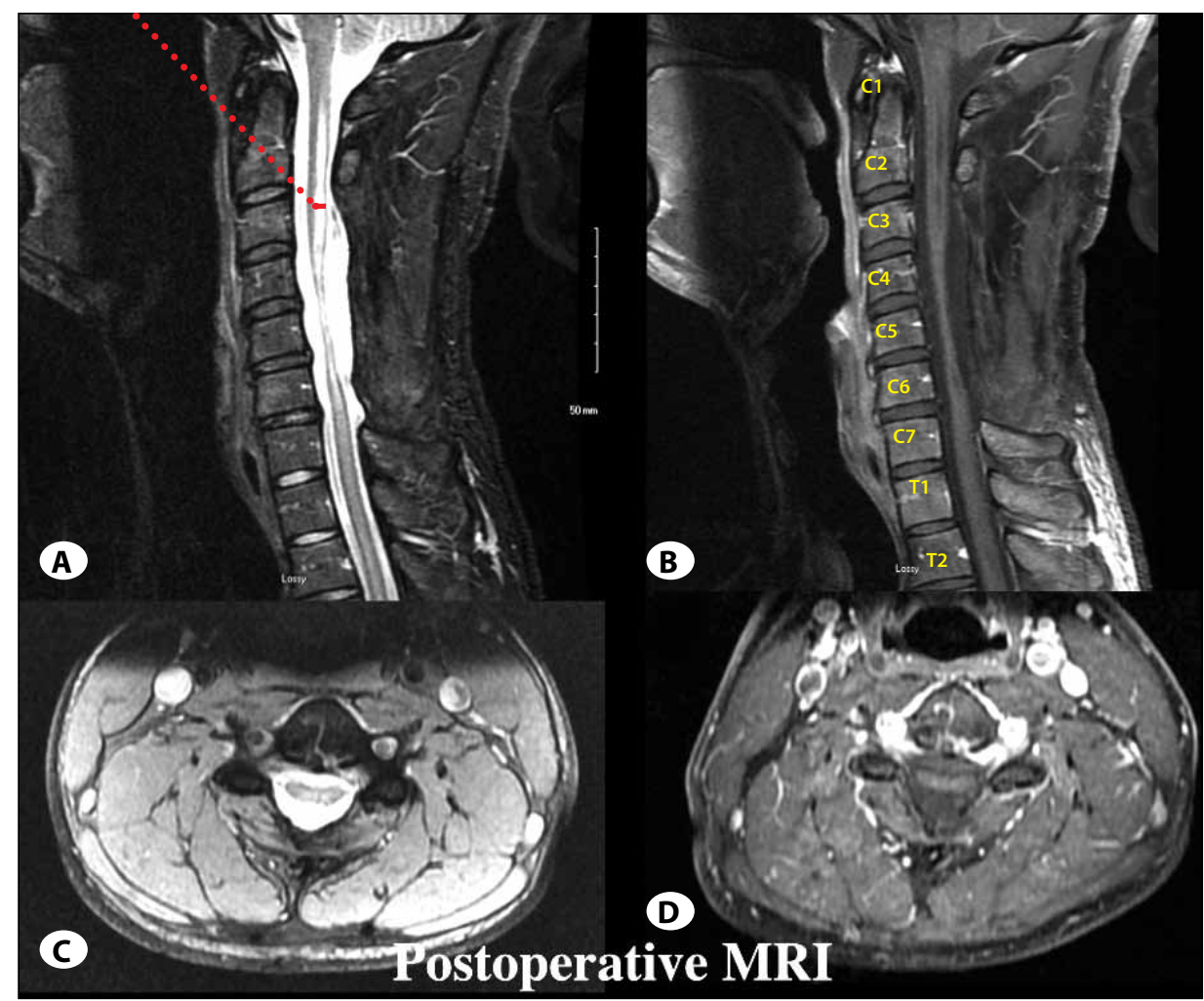

Figure 2: Postoperative images; A) sagittal T2 weighted MRI demonstrates resolution of the mass effect and the syrinx, B) postcontrast sagittal T1 weighted MRI reveals gross total resection. C) T2 weighted axial MRI, D) postcontrast T1 weighted axial MRI. 